\title{
Kepuasan Pasien akan Pelayanan Keperawatan di Ruang Rawat Inap Rumah Sakit Umum Daerah Buntok, Kalimantan Tengah
}

\author{
Warjiman $^{1}$, Yuli Sulistiyo ${ }^{2}$, Lucia Andi Chrismilasari ${ }^{3}$ \\ ${ }^{1,2}$ Dosen STIKES Suaka Insan Banjarmasin, Kalimantan Selatan \\ ${ }^{3}$ Perawat Rumah Sakit Umum Daerah Jaraga Sasameh Bunto, Kalimantan Tengah \\ Email: warjiman99@gmail.com
}

\begin{abstract}
Patient satisfaction is a level of patient feeling that arises as a result of the performance of the health services he gets, especially after the patient has compared it with what he expected. Patients will feel satisfied if the performance of the health services they receive equals or exceeds their expectations and vice versa, dissatisfaction or feelings of disappointment will arise if the performance of the health services they receive is not in accordance with their own performance. Nursing service satisfaction at Jaraga Sasameh Hospital has decreased by 1.75\% from two measurements time in October-December 2018 and January-March 2019. This study aims to identify description of patient satisfaction with nursing services in the inpatient room at Jaraga Sasameh Hospital, Buntok, Center Kalimantan. This research was a descriptive-quantitative study with survey data collection. The research sample was taken by using purposive sampling technique with a total of 80 respondents. Validity and reliability tests were conducted on 30 respondents. The results were analyzed using descriptive statistics by displaying the frequency distribution table. This study shows that the majority of respondents' assessment of patient satisfaction is in the satisfied category (58.75\%), followed by very satisfied (41.25\%) and very dissatisfied and dissatisfied $(0 \%)$. The results showed that the majority of patients were satisfied to be treated in the inpatient room of the regional general hospital.
\end{abstract}

Keywords: Patient Satisfaction, Nursing Services, Inpatient Rooms, Regional Public Hospitals

\begin{abstract}
Abstrak
Kepuasan pasien adalah suatu tingkat perasaan pasien yang timbul sebagai akibat dari kinerja layanan kesehatan yang diperolehnya, terutama setelah pasien membandingkannya dengan apa yang diharapkannya. Pasien akan merasa puas apabila kinerja layanan kesehatan yang diperolehnya sama atau melebihi harapannya dan sebaliknya ketidakpuasan atau perasaan kecewa akan muncul jika kinerja layanan kesehatan yang diperolehnya itu tidak sesuai dengan kinerjanya sendiri. Kepuasan pelayanan keperawatan di Rumah Sakit Jaraga Sasameh mengalami penurunan sebanyak $1.75 \%$ dari dua kali pengukuran bulan oktoberdesember 2018 dan januari-maret 2019. Penelitian ini bertujuan untuk mengidentifikasi gambaran kepuasan pasien akan pelayanan keperawatan di ruang rawat inap di RSUD Jaraga Sasameh Buntok, Kalimantan Tengah. Penelitian ini adalah penelitian deskriptif-kuantitatif dengan pengumpulan data secara survey. Pengambilan sampel penelitian dilakukan dengan menggunakan teknik purposive sampling dengan jumlah 80 responden. Uji validitas dan reliabilitas dilakukan terhadap 30 responden. Hasil penelitian dianalisa dengan menggunakan statistik deskriptif dengan menampilkan tabel distribusi frekuensi. Penelitian ini menunjukkan bahwa mayoritas penilaian responden tentang kepuasan pasien berada di kategori puas $(58.75 \%)$, disusul dengan kategori sangat puas (41.25\%) dan sangat tidak puas dan tidak puas $(0 \%)$. Hasil penelitian menunjukkan bahwa mayoritas pasien merasa puas dirawat di ruang rawat inap rumah sakit umum daerah.
\end{abstract}

Kata Kunci: KepuasanPasien, Pelayanan Keperawatan, Ruang Rawat Inap, Rumah sakit umum daerah 


\section{Pendahuluan}

Badan kesehatan dunia (WHO) telah menetapkan bahwa kesehatan merupakan investasi, hak, dan kewajiban setiap manusia. Kutipan tersebut tertuang dalam Undang-Undang No. 36 tahun 2009 tentang kesehatan yang menetapkan bahwa setiap orang berhak mendapatkan pelayanan kesehatan. Oleh karena itu, setiap individu keluarga dan masyarakat berhak memperoleh perlindungan terhadap kesehatannya, dan negara bertangggung jawab mengatur agar terpenuhi hak hidup sehat bagi penduduknya termasuk bagi masyarakat miskin dan tidak mampu yang kemudian direalisasikan melalui jaminan kesehatan bagi seluruh warga negara di Indonesia. Agar dapat menjadi tempat pelayanan kesehatan pilihan dan mendapatkan loyalitas masyarakat, penting bagi setiap tempat pelayanan kesehatan untuk meningkatkan mutu pelayanannya (Setiawan, 2011).

Mutu pelayanan kesehatan ialah tingkat kesempurnaan pelayanan kesehatan yang diselenggarakan, yang disatu pihak menimbulkan kepuasan pada setiap pasien dengan tingkat kepuasan rata-rata penduduk, serta dipihak lain tata cara penyelenggaraan sesuai dengan standart dan etik profesi yang telah ditetapkan. Bagi pasien, mutu yang baik dikaitkan dengan sembuhnya dari sakit atau berkurangnya rasa sakit, kecepatan pelayanan, keramahtamahan dan tarif pelayanan yang murah. Sebaliknya pasien menganggap mutu pelayanan jelek bila penyakitnya tidak sembuh-sembuh, antri lama, petugas kesehatannya tidak ramah.

Kepuasan pasien secara umum dapat diartikan sebagai hasil penilaian pasien berdasarkan perasaannya terhadap penyelenggaraan pelayanan kesehatan di rumah sakit. Kepuasan merupakan tingkat perasaan seseorang setelah membandingkan kinerja (atau hasil) yang dia rasakan dibandingkan dengan harapannya (Kotler,1997).

Peraturan Menteri Kesehatan Nomor 54 Tahun 2014 tentang rumah sakit, rumah sakit adalah institusi pelayanan kesehatan yang menyelenggarakan pelayanan kesehatan perorangan secara paripurna yang menyediakan pelayanan rawat inap, rawat jalan, dan gawat darurat. RSUD Jaraga Sasameh merupakan rumah sakit kelas C sejak tahun 2012, milik pemerintah kabupaten Barito Selatan dengan UPT RSUD Jaraga Sasameh. Dengan surat keputusan kepala Dinas Penanaman Modal dan PTSP Kabupaten Barito Selatan dengan nomor : 530-570/0001/IV.I/DPM-PTSP/IV/2018 tentang surat ijin operasional RSUD Jaraga Sasameh.

Departeman Kesehatan Republik Indonesia (2009) menyatakan bahwa standar nasional nilai atau angka ideal yang seharusnya dicapai suatu rumah sakit dikatakan baik dan efisien apabila Bed Occupancy Rate (BOR) berada pada $60-80 \%$. Hal ini juga menunjukkan bahwa dalam kurung waktu 5 tahun Rumah Sakit ini belum dapat memenuhi target nilai BOR yang ditetapkan oleh Depkes. Hal ini dimungkinkan karena pelayanaan yang diberikan RSUD Jaraga Sasameh belum sesuai dengan harapan pasien. Rendahnya pencapaian BOR tersebut dapat dikarenakan tingkat kepuasan pasien terhadap pelayanan rumah sakit masih kurang, hal ini ditandai dengan diperolehnya informasi dari beberapa pasien terkait kualitas pelayanan RSUD Jaraga Sasameh. Laporan menyatakan bahwa perawat dalam melayani pasien bersikap kurang sopan dan tidak ramah, tindakan medis kurang cepat, perawat tidak selalu memantau atau mengobservasi keadaan pasien secara rutin, informasi tentang penyakit yang disampaikan perawat kurang jelas, dokter menerangkan penyakit kurang jelas terhadap pasien, dokter kurang perhatian terhadap pasien, dokter kurang mendengar keluhan pasien, dan pelayanan kurang memuaskan.

Hasil survei pendahuluan yang dilakukan peneliti terhadap 5 pasien rawat jalan dan rawat inap, menyatakan bahwa perawat dalam melayani pasien bersikap kurang ramah dan kurang sabar. Perawat masih memandang status sosial dalam merawat pasien, dokter tidak cepat dalam menangani keluhan, perawat tidak sigap, apabila infus pasien habis kemudian keluarga pasien memanggil perawat untuk menggantinya pasti perawat datangnya lama sekali apalagi pada saat jam istirahat susah sekali perawat untuk dipanggil dan ditemui karena mereka tidak ada diruangan padahal seharusnya jam istirahat mereka harus tetap ada untuk siap melakukan tugasnya melayani pasien, karena sudah ada jam mereka begantian untuk menjaga. Pasien juga mengatakan bahwa mereka kesulitan berinteraksi dengan dokter dan perawat, ruangannya panas, kemudian selama kita dirawat di rumah sakit seprai (alas tempat tidur) tidak pernah diganti, makanan yang disediakan oleh rumah sakit tidak sesuai dengan penyakit yang diderita oleh pasien, kemudian tempat parkir kendaraan tidak mencukupi, jika pasien banyak yang berobat. Hal ini didukung oleh penelitian yang dilakukan Haryati (2004) di RSUD Langsa yang menunjukkan bahwa mutu pelayanan kesehatan berpengaruh pada kepuasan pasien dalam menggunakan pelayanan kesehatan, penelitian Tarigan (2009) yang dilakukan di RSUD Dr. H. Kumpulan Pane Tebing Tinggi yang menyatakan bahwa assurance (jaminan) berpengaruh terhadap kepuasan. Selanjutnya penelitian yang telah dilakukan oleh Rambe (2014) di RS Padang 
Sidempuan menunjukkan kepuasan pasien dalam menggunakan pelayanan kesehatan khususnya di ruang rawat inap berpengaruh besar terhadap akreditasi rumah sakit tersebut.

Data temuan yang dipaparkan di atas menunjukkan bertapa pentingnya menggali lebih dalam dan rinci kepuasan pasien yang di rawat di rawat Inap RSUD Jaraga Sasameh.

\section{Metode Penelitian}

Jenis penelitian ini adalah deskriptif dengan rancangan penelitian kuantitatif. Penelitian ini biasanya bertolak dari suatu teori yang kemudian diteliti, dihasilkan data, kemudian dibahas dan diambil kesimpulan (Notoatmodjo, 2010). Sampel pada penelitian ini adalah pasien rawat inap yang dirawat di RSUD Jaraga Sasameh. Teknik pengampilan sampel yang digunakan dalam penelitian ini adalah purposive samplin gdengan menggunakan kriteria inklusi dan ekslusi. Sampel dalam penelitian ini sebanyak 80 responden.
Alat ukur penelitian ini adalah kuesioner. Instrument penelitian berisi 20 item pertanyaan yang berkaitan dengan kepuasaan pasien, terdiri dari pertanyaan favorabel dan unfavorabel dengan mengacu pada skala kepuasan terdiri dari aspek penilaian : tangible, reability, responsiveness, assurance, emphaty. Penilaian dilakukan dengan menggunakan skala Likert dengan pertanyaan favorabel Sangat Puas $=4$, Puas $=3$, Tidak Puas $=2$ Sangat Tidak Puas $=1$ dan Unfavorabel Sangat Puas=1, Puas=2, Tidak Puas $=3$ Sangat Tidak Puas $=4$.

Uji Validitas intrumen penelitian dengan product moment. Hasil Uji Validitas kuesioner instrumen 20 dari 25 pernyataan dalam rentang 0,640 - 0,864, dan Reliabilitas ialah 0,963, sehingga kuesioner instrumen dinyatakan valid dan reliabel dan dapat atau layak digunakan untuk penelitian. Data yang telah dikumpulkan kemudian dianalisa secara univariat dengan menggunakan distribusi frekuensi, hasil ukur untuk kategori Sangat Tidak puas $=20-34$, Tidak puas $=35-50$, Puas $=51-66$, Sangat puas $=67-80$ $\%$.

\section{Hasil Penelitian}

a. Karakteristik Responden

Karakteristik responden yang ikut serta dalam penelitian ini ditunjukkan dalam tabel di bawah ini.

Tabel 1.1. Karakteristik Responden dilihat dari Usia, Jenis Kelamin dan Tingkat Pendidikan

\begin{tabular}{|c|c|c|c|c|c|}
\hline \multicolumn{4}{|c|}{ Karakteristik } & Frekuensi & Persentase \\
\hline \multirow[t]{5}{*}{$\mathbf{I}$} & Usia & \multicolumn{2}{|c|}{$<25$ tahun } & 6 & $7.5 \%$ \\
\hline & & \multicolumn{2}{|c|}{$25-35$ Tahun } & 23 & $28.75 \%$ \\
\hline & & \multicolumn{2}{|c|}{$36-45$ Tahun } & 18 & $22.5 \%$ \\
\hline & & \multicolumn{2}{|c|}{$\begin{array}{c}>45 \text { Tahun } \\
\text { (Depkes, 2005) }\end{array}$} & 33 & $42.15 \%$ \\
\hline & \multicolumn{3}{|c|}{ Total } & 80 & $100 \%$ \\
\hline \multirow[t]{3}{*}{ II } & Jenis Kelamin & \multicolumn{2}{|c|}{ Laki-laki } & 44 & $55 \%$ \\
\hline & \multirow{2}{*}{\multicolumn{3}{|c|}{$\begin{array}{l}\text { Perempuan } \\
\text { Total }\end{array}$}} & 36 & $45 \%$ \\
\hline & & & & 80 & $100 \%$ \\
\hline \multirow[t]{5}{*}{ III } & Tingkat Pendidikan & \multicolumn{2}{|c|}{ Sekolah Dasar } & 10 & $12.5 \%$ \\
\hline & & $\begin{array}{l}\text { Sekolah } \\
\text { Pertama }\end{array}$ & Menengah & 10 & $12.5 \%$ \\
\hline & & $\begin{array}{l}\text { Sekolah } \\
\text { Atas }\end{array}$ & Menengah & 40 & $50 \%$ \\
\hline & \multicolumn{3}{|c|}{ Perguruan Tinggi } & 20 & $25 \%$ \\
\hline & \multicolumn{3}{|c|}{ Total } & 80 & $100 \%$ \\
\hline
\end{tabular}

Tabel 1.1 menunjukkan bahwa mayoritas responden memiliki usia berkisar antara $>45$ tahun (33; $42.15 \%$ ), berjenis kelamin laki-laki $(44 ; 55 \%)$ dan memiliki tingkat pendidikan terakhir sekolah menengah atas (SMA) (40: 50\%). 


\section{b. Analisis Univariat}

Hasil pengukuran variable kepuasan pasien (responden) terhadap pelayanan keperawatan dapat dilihat pada tabel 1.2 di bawah ini.

Tabel 1.2 Hasil pengukuran kepuasan responden terharap pelayanan keperawatan di ruang rawat inap.

\begin{tabular}{ccc}
\hline Kepuasan Pasien di Rawat Inap & Frekuensi & Persentase (\%) \\
\hline Sangat Tidak Puas & 0 & $0 \%$ \\
Tidak Puas & 0 & $0 \%$ \\
Puas & 47 & $58,75 \%$ \\
Sangat Puas & 33 & $41,25 \%$ \\
\hline Total & $\mathbf{8 0}$ & $\mathbf{1 0 0} \%$ \\
\hline
\end{tabular}

Tabel 1.2 menunjukkan hasil pengukuran kepuasan pasien terhadap pelayanan keperawatan di ruang rawat inap. Hasil penelitian menunjukkan bahwa mayoritas pasien rawat inap merasa puas dengan perawatan yang diberikan $(47,58.75 \%)$ di ruang rawat inap selama mereka tinggal dan dirawat di sana.

\section{Pembahasan}

Penilaian responden tentang kepuasannya dirawat di ruang rawat inap rawat inap RSUD Jaraga Sasameh Tahun 2019 menunjukkan kategori sangat tidak puas dan tidak puas sebanyak 0 responden $(0 \%)$, kategori sangat tidak puas dan tidak puas yaitu sebanyak 0 responden $(0 \%)$ dan kategori puas yaitu sebanyak 47 responden $(58,75 \%)$, dan kategori sangat puas sebanyak 33 responden $(41,25 \%)$.

Kepuasan pasien dinilai berdasarkan interpretasi responden terhadap kesesuaian antara harapan yang diterima, meliputi kecepatan/kesegeraan petugas dalam memberikan pelayanan, ketersediaan sarana dan prasarana yang dibutuhkan pasien dan keramahan petugas dalam memberikan pelayanan keperawatan. Indikator kepuasan pasien, meliputi kepuasan pasien berdasarkan bukti fisik, kehandalan, daya tanggap, jaminan, dan empati. Hasil penelitian berdasarkan tabel 1.2 data variabel kepuasan pasien didapatkan bahwa 47 responden $(58,75 \%)$ menyatakan puas dan 33 responden menyatakan Sangat puas $(41,25 \%)$, sehingga dapat disimpulkan bahwa sebagian besar pasien merasa puas terhadap pelayanan keperawatan.

Item pernyataan yang dinilai terhadap kepuasan pasien pada penelitian ini berdasarkan aspek dimensi mutu pelayanan, terdiri dari kenyamanan yang meliputi kenyamanan sarana dan prasarana, hubungan pasien dengan perawat menyangkut keramahan, dan informasi yang diberikan perawatan, pengetahuan dan kompetensi yang meliputi kecepatan pelayanan, keterampilan perawat, kejelasan dalam memberikan informasi terkait dengan penyakit dan pengobatan, ketepatan pelayanan, efektivitas pelayanan, serta keamanan pasien.
Pelayanan keperawatan merupakan pusat kegiatan yang paling banyak terjadi interaksi antara perawat dengan pasien. Persepsi pasien terhadap mutu pelayanan keperawatan akan menimbulkan kepuasan pasien terhadap pelayan yang diterima (Suryawati, 2004).

Hasil penelitian ini didukung oleh pendapat Pohan (2007), yang menyatakan bahwa dalam pengalaman sehari-hari ketidakpuasan terhadap sikap, kurang komunikasi dan informasi perawat atau petugas medis, lamanya proses mendapatkan pelayanan, serta kecepatan pelayanan. Kepuasan pasien akan timbul dari kesan pertama pasien terhadap pelayanan keperawatan yang diberikan.

Kepuasan pasien dapat diukur melalui indikator kepuasan pasien terhadap pelayanan yang diberikan. Hasil penelitian ini sesuai dengan hasil Rawat Inap RSUD Jaraga Sasameh, yaitu adanya unsur terendah dari indeks kepuasan masyarakat dalam memberikan pelayanan di Rawat Inap RSUD Jaraga Sasameh adalah kecepatan pelayanan keperawatan dan kejelasan perawat terhadap prosedur informasi.

Penelitian ini sesuai dengan pendapat Sabarguna (2008) yang mengatakan bahwa salah satu aspek indikator kepuasan pasien, yaitu pengetahuan dan kompetensi teknis yang meliputi: kecepatan pelayanan, serta pengetahuan dalam memberikan informasi. Pendapat lain yang sesuai dengan hasil penelitian ini adalah pendapat menurut Pohan (2007) bahwa faktor-faktor yang memengaruhi kepuasan pasien antara lain, yaitu dari segi pelayanan, meliputi kecepatan pelayanan.

Pelayanan dianggap baik apabila dalam memberikan pelayanan lebih memperhatikan kebutuhan pasien sesuai dengan standar dan kode etik profesi. Kepuasan pasien akan timbul dari kesan pertama pasien terhadap pelayanan keperawatan yang diberikan. 


\section{Kesimpulan}

Penelitian ini menunjukkan bahwa kepuasan pasien terhadap pelayanan keperawatan di ruang rawat inap kelas III di RSUD Jaraga Sasameh tahun 2019 masuk dalam kategori puas $(58,75$ $\%)$.

Penelitian ini menyarankan agar rumah Sakit Umum Daerah dapat mempertahankan dan terus meningkatkan mutu pelayanan keperawatan yang telah dinilai baik dan memuaskan. Meningkatkan keramah-tamahan dan kesopanan sebagai bentuk rasa kepedulian mendalam dalam memberikan pelayanan dengan baik sebagai upaya peningkatan mutu layanan dalam usaha memberikan pelayanan yang lebih baik bagi seluruh lapisan masyarakat sebagai pengguna fasilitas kesehatan.

\section{Acknowledgement}

Terima kasih kepada pimpinan dan jajaran manajemen Rumah Sakit Umum Daerah Jaraga Sasameh, Buntok-Kalimantan Tengah serta STIKES Suaka Insan Banjarmasin.

\section{Daftar Pustaka}

Alamri, Nurdjana. (2015). Layanan Bimbingan Kelompok Dengan Teknik Self Management Untuk Mengurangi Perilaku terlambat Masuk Sekolah (Studi Pada Siswa Kelas X SMA 1 Gebog Tahun 2014/2015).[Online],

(http://jurnal.umk.ac.id/index.php/gusjigan g/article/view/259, diakses pada 14 Nopember 2019 Pukul 10.00 WIB).

Azwar, Azrul. (1996). Menjaga Mutu Pelayanan Kesehatan. Jakarta:pustaka sinar harapan.

Budiman \& Riyanto A. (2013). Kapita Selekta Kuisioner Pengetahuan Dan Sikap Dalam Penelitian Kesehatan. Jakarta : Salemba Medika pp 66-69.

Griffiths et al. (2008). International Relations: The Key Concepts Second Edition. New York: Routledge

Haryanto, A. (2009). Hubungan Antara Mutu Pelayanan Kepuasan Dengan Kepuasan Pasien di Puskesmas Ngawen 1. Skripsi: Yogyakarta

Herlambang. S, Murwarni. A (2012). Cara Mudah Memahami Manajemen Kesehatan dan Rumah Sakit. Yogyakarta. Gosyen.

Kemenkes RI. (2012). Survei Kesehatan Dasar Indonesia. Jakarta: Kementrian Kesehatan Republik Indonesia.

Khoiri, A.N. \& Hermastutik, K., (2014). Hubungan Mutu Pelayanan Keperawatan
Dengan Kepuasan Pasien Pengguna Kartu BPJS Kesehatan di Puskesmas Mojowarno Kabupaten Jombang ( The Correlation The Quality Of Nursing Service And The Satisfaction Of The Patients Holding Bpjs Card In Health Service Center, Mojowarno-Jombang ). (December)

Koentjoro, Tjahjono. (2007). Regulasi Kesehatan di Indonesia. Penerbit Andi. Yogyakarta.

Kotler,Philip. (2005), Manajemen Pemasaran. Edisi Kesebelas jilid satu. Jakarta: PT Indeks, Gramedia.

Notoatmodjo, S. (2011). Kesehatan Masyarakat. Jakarta: Rineka Cipta

Nursalam. (2007). Manajemen Keperawatan dan Aplikasinya. Penerbit Salemba Medika, Jakarta.

Nursalam. (2014). Manajemen Keperawatan: Aplikasi Dalam Praktik Keperawatan Profesional. Jakarta: Salemba Medika.

Pohan, I. S. (2007). Jaminan Mutu Pelayanan Kesehatan: Dasar - Dasar Pengertian dan Penerapan. Cetakan I, EGC: Jakarta

Sabarguna, B.S. (2008). Quality Assurance Pelayanan Rumah Sakit. Sagung Seto: Jakarta

Sulistiyono, P. (2014). Persepsi Pasien Tentang Pelayanan BPJS Di RSI Muhammadiyah Kendal. Skripsi Program Studi S1 Fakultas Ilmu Keperawatan Dan Kesehatan Universitas Muhammadiyah Semarang. (Online).http://digilib.unimus.

PHARMACONJurnal Ilmiah Farmasi UNSRAT Vol. 4 No. 4 November 2015 ISSN $2302 \quad-\quad 2493 \quad 251$ ac.id/files/disk1/153/jtptunimu s-gdl-puji sulist-7638-1-3.filek.pdf Diakses pada tanggal 27 Nopember 2019.

Suryawati. (2004). Pengukuran Kepuasan Pasien. Kilat Press: Semarang

Tijptono, F dan Diana, A. (2007). Service, Quality \& Statisfaction. Edisi II, ANDI: Yogyakarta.

Triwibowo. (2013). Manajemen pelayanan keperawatan di rumah sakit. Jakarta: TIM.

Umar, Husein. (2002). Metode Penelitian Bisnis. Bandung: Alfabeta.

Undang-Undang Nomor 36 Tahun 2009 Tentang Kesehatan.

Undang-Undang Nomor 44 Tahun 2009 Tentang Rumah Sakit.

Wijono, D. (2000). Manajemen Mutu Pelayanan Kesehatan.Airlangga University Press: Surabaya. 